IZA DP No. 6837

Frontier Issues of the Political Economy of Migration

Gil S. Epstein

September 2012

Forschungsinstitut zur Zukunft der Arbeit Institute for the Study of Labor 


\title{
Frontier Issues of the Political Economy of Migration
}

\author{
Gil S. Epstein \\ Bar-Ilan University, \\ IZA and CReAM
}

\section{Discussion Paper No. 6837 \\ September 2012}

\author{
IZA \\ P.O. Box 7240 \\ 53072 Bonn \\ Germany \\ Phone: +49-228-3894-0 \\ Fax: +49-228-3894-180 \\ E-mail: iza@iza.org
}

\begin{abstract}
Any opinions expressed here are those of the author(s) and not those of IZA. Research published in this series may include views on policy, but the institute itself takes no institutional policy positions.

The Institute for the Study of Labor (IZA) in Bonn is a local and virtual international research center and a place of communication between science, politics and business. IZA is an independent nonprofit organization supported by Deutsche Post Foundation. The center is associated with the University of Bonn and offers a stimulating research environment through its international network, workshops and conferences, data service, project support, research visits and doctoral program. IZA engages in (i) original and internationally competitive research in all fields of labor economics, (ii) development of policy concepts, and (iii) dissemination of research results and concepts to the interested public.
\end{abstract}

IZA Discussion Papers often represent preliminary work and are circulated to encourage discussion. Citation of such a paper should account for its provisional character. A revised version may be available directly from the author. 
IZA Discussion Paper No. 6837

September 2012

\section{ABSTRACT \\ Frontier Issues of the Political Economy of Migration}

Migration has a strong economic impact on the sending and host countries. Since individuals and groups do not benefit equally from migration, interest groups emerge to protect and take care of their narrow self-interests and compete for rents generated by migration. Narrow selfinterests may be present not only for interest groups but also for ruling politicians and civil servants. In this paper we consider how political culture is important for determining policy and how interest groups affect, via a lobbying process, the choice of public policy. We also consider how interest groups and lobbying activities affect assimilation and attitudes towards migrants and international trade. The narrow interests of the different groups may cause a decrease in social welfare, in some cases, and may enhance welfare in other situations.

JEL Classification: F22, P48, O15

Keywords: migration, political economy, culture, minorities, politicians

Corresponding author:

Gil S. Epstein

Department of Economics

Bar-Ilan University

Ramat Gan

Israel

E-mail: Gil.Epstein@Biu.ac.il 


\section{Introduction}

Political economy plays an important role in migration. Basic economic theory provides many predictions with regard to the costs and benefits of migrants to home and host countries. Migration affects production, employment and wages, assimilation and attitudes towards migration, economic behavior of the local population and migrants, international trade, etc. in both the host and home counties. Assuming that the goal is to maximize social welfare countries could, in theory, derive their optimal economic policy. However, reality is not always what the theory predicts.

How is it possible that two countries with similar economic circumstances have different outcomes from a similar migration quota or may enact different migration policies? How is it that migration policy shifts in a short period of time while there have been very small changes in the economic environment? Is this simply a result of a change in the ruling politician or coalitions? Why do similar countries elect parties with very different political platforms? The answer to these and many other questions are related to the political economy environment.

Classic economic analysis assumes that individuals and voters maximize utility, capital owners maximize profits and politicians maximize social welfare. This paper shows that if we build political elements into the maximization process our predications with regard to agents' behavior may change in interesting and significantly ways. As a result, our model predictions may be appended and may decrease or increase welfare.

Do ruling politicians and government really only want to maximize social welfare or do they also care about their narrow self interest and re-election? Do the leaders of the capital owners and the workers' union care only about the well being of 
the capital owners and the workers? Do the representatives of the migrants want to maximize the migrants' utility? The answers to these questions are not simple since no two individuals, no two workers, no two employers, or two migrants are identical. Each benefits or loses in different ways from policy.

The outcomes from migration are not negligible. Migration has a strong economic impact and as such creates many rents for different groups in the economy. As a result of the important impact migration has on the economy, migration policy has been an important issue in elections around the world. On the one hand, capital owners wish to increase the number of migrants in order to increase profits. On the other hand, the local population (workers/voters) may want to increase migration to help in certain markets while in other markets they want to decrease migration so not to depress wages and employment. Assimilation may be costly for the local population and may also be costly for the migrants who want to hold on to their heritage and customs.

Rents from migration are high and are not divided equally among and within the different groups that benefit (or are harmed) from it. Since rents exist and are not divided proportionally, they are contestable. When contesting rents the efforts invested by different groups differ according to their workers' objectives: do representatives care only about the workers or do they also care about their own interests? What is the objective of the representative of the capital owners? What do the migrants want? Do they want to fully assimilate in order to increase wages and employment or do they want to hold on to their heritage and customs while paying the cost of less assimilation? Many of the answers to these questions are politically oriented. The contest over the rents creates investment in non-productive activities employing resources that may have been productively engaged if the rents were not 
contestable. Therefore, these activities are wasteful resources and may decrease output and social welfare.

In the following paper we wish to shed light on some of the issues presented above using the public choice literature on political economy. The public choice approach explicitly incorporates actors who vary in objectives into the modeling. In the next section we posit a simple theoretical model that presents the contest over rents generated by migration. We also consider the determination of public policy by a government that has an objective function which is a weighted average of the expected social welfare and its own narrow interests. We use this simple model to explain results presented later in the paper. We then divide our analysis into two main sections: the host country and the sending country. The section regarding the host country deals with the issues of voters' attitudes to migration, the determination of migration quotas, migrants' assimilation and the role of international trade. We discuss some political economy issues from the sending country and finally present concluding remarks while pointing to new areas that need development.

\section{A Basic Model of the Political Economy of Migration}

Politicians, while making decisions, may compromise social welfare, this may be in order to increase social welfare in the long run, or to increase their own wellbeing. Politicians need recourses for campaign elections and to satisfy capital owners and voters. They want to be re-elected and the need for campaign resources can affect the decision making of the politicians and their ruling. One could argue that even if a politician only wants to maximize social welfare he may still compromise it in order to be re-elected. Consider a Prime Minister or President who wants to be re-elected. The Prime Minister's objective is only the enhancement of social welfare. Since he 
wants to be re-elected and wishes to maximize social welfare, he must believe that he is the best candidate for the job and if chosen social welfare will be maximized. Thus, the Prime Minister believes that if a different candidate is chosen, social welfare will be lower than if he is elected.

In the case of a struggle over migration policy we assume that the capital owners want to increase the number of legal migrants entering the economy while the Prime Minister knows that social welfare is maximized with a status-quo policy. Namely, he knows that it is best not to change the quota of legal migrants. However, the Prime Minister is aware of the fact that if he will not increase the migration quota the capital owners will not back him in the next elections, and will transfer all their election campaign funds to his opposition. In such a case, the Prime Minister will most probably lose the elections and his opposition will come into power. Since he only wishes to maximize social welfare, he believes that if he loses the elections then social welfare will decrease as a result of the opposition's political platform. Therefore, he may decide to increase the migration quota in order to increase his chances of winning. He decides to do so only for the benefit of society! ${ }^{2}$

This example presented a Prime Minister who wishes only to maximize social welfare and who, in the end, favors a policy which benefits the capital owners to ensure his reelection. Note that this Prime Minister is assumed to only want to maximize social welfare. If we had assumed that the politician does not only care about social welfare but also about his own wellbeing it is obvious that he will pass such legislation.

Formally we could model such a decision making process as follows. Denote the decision maker's objective by $G($.$) . To simplify we assume that there are two$ interest groups: group 1 and group 2. As in Epstein and Nitzan (2006, 2007), suppose 
that a policy $I$ is proposed by the government (by a ruling politician or by a bureaucrat). The two interest groups compete on the approval or rejection of the proposed policy I. Approval is the preferred policy of one group whereas rejection of the proposed policy is the preferred policy of the other player. Approval implies that player 1 wins the contest. The present discounted value of the preferred outcome to player $i$ is equal to $u_{i}$ and the value of this outcome to his opponent, player $j$, is equal to $v_{j}$. Approval of the proposed policy is associated with a positive payoff for player $i$, since, by assumption, $u_{i}>v_{i}$. Similarly, rejection is associated with a positive payoff for player $j$, since, $u_{j}>v_{j}(i, j=1,2)$.

Note that, in general, the players' payoffs corresponding to the approval and rejection of the policy $I$ depend on $I$. Player 1's preferred contest outcome, namely the approval of $I$, is reached with probability $\operatorname{Pr}_{1}$. The probability of player 2's preferred contest outcome is $\operatorname{Pr}_{2}, \operatorname{Pr}_{2}=1-\operatorname{Pr}_{1}$. These winning probabilities depend on the efforts made by the two contestants, $x_{1}$ and $x_{2}: \operatorname{Pr}_{1}\left(x_{1}, x_{2}\right)$ and $\operatorname{Pr}_{1}\left(x_{2}, x_{1}\right)$. Increasing $x_{1}$ increases $\operatorname{Pr}_{1}$ and increasing $x_{2}$ will decrease $\operatorname{Pr}_{1}\left(\frac{\partial \operatorname{Pr}_{i}}{\partial x_{i}}>0\right.$ and $\left.\frac{\partial \operatorname{Pr}_{i}}{\partial x_{j}}<0, i, j=1,2\right)$. The probability function is frequently called in the literature "a Contest Success Function" (CSF) (see for example Tullock (1980) and Hillman and Riley (1989)). ${ }^{3}$

The resources invested in the contest can be seen as wasted if they are only invested in order to win the contest and do not provide other benefits.

The expected net payoff of the risk-neutral player $i$ is equal to:

$$
E\left(w_{i}\right)=\operatorname{Pr}_{i} u_{i}(I)+\operatorname{Pr}_{j} v_{i}(I)-x_{i} \quad \mathrm{i}, \mathrm{j}=1,2, \mathrm{i} \neq \mathrm{j}
$$

Denote by $n_{i}=\left(u_{i}-v_{i}\right)$ the stake of player $i$ (his benefit from winning the contest). A player's stake is secured when he wins the contest, that is, when his preferred policy 
is the outcome of the contest. Recall that for one player the desirable outcome is associated with the approval of the proposed policy while for the other player the desirable outcome is realized when the proposed policy is rejected. The expected net payoff of interest group $i$ can be rewritten as follows:

$$
E\left(w_{i}\right)=v_{i}(I)+\operatorname{Pr}_{i} n_{i}(I)-x_{i} i=1,2
$$

In general, the stakes of the contestants may differ, one of them having an advantage over the other in terms of his benefit from winning the contest. Since $v_{i}(I)$ is the minimum benefit obtained by interest group/contestant $i$, regardless of the outcome of the contest, we can concentrate on his expected net payoff, disregarding this value. Such a simplification will no longer be legitimate when changes in the proposed policy $I$ are allowed to affect the different contest outcomes. At this stage, however, the objective function of the contestant can be written as

$$
E\left(u_{i}\right)=\operatorname{Pr}_{i} n_{i}(I)-x_{i} \quad i=1,2
$$

We will refer to this expression as the net payoff of the contestant.

Each of the groups determines the optimal level of investment $x$ that maximizes the net payoff of the contestant. The outcome of such a contest determines the optimal Nash equilibrium investments $\left(x_{i}^{*}, x_{j}^{*}\right)$ of each of the players. The equilibrium investments are a function of the contest success function and the stakes of the contests. The politicians many times determine the type of contests that will be played between the interest groups (for example, the all pay action or a generalized logic contest success). The politicians determine the contest such that it will maximize its objective function. The stakes of the contestants are a function of the proposed policy. 
To illustrate let us consider the case where the contest success function is the non-discriminating logit function (Tullock, 1980):

$$
\operatorname{Pr}_{i}=\frac{x_{i}}{x_{i}+x_{j}} \text { for all } j \neq i \text { and } i, j=1,2
$$

Solving for the first order condition ${ }^{4}$ for both players, we obtain Nash Equilibrium efforts $\left(x_{i}^{*}, x_{j}^{*}\right)$, the probability of winning the contests $\left(\operatorname{Pr}_{i}^{*}, \operatorname{Pr}_{j}^{*}\right)$, the total efforts invested in the contests (the rent dissipation $-X^{*}=x_{1}^{*}+x_{2}^{*}$ ), and the expected net payoffs in the contest equal:

$$
x_{i}^{*}=\frac{n_{i}^{2} n_{j}}{\left(n_{1}+n_{2}\right)^{2}}, \operatorname{Pr}_{i}^{*}=\frac{n_{i}}{n_{1}+n_{2}}, \quad X^{*}=\frac{n_{i} n_{j}}{n_{i}+n_{j}} \text { and } E\left(u_{i}^{*}\right)=\frac{n_{i}^{3}}{\left(n_{i}+n_{j}\right)^{2}}
$$

Equation (5) demonstrates the role the stakes $\left(n_{1}\right.$ and $\left.n_{2}\right)$ have in determining outcomes. Under this CSF, the interest group with the higher stake will invest the largest effort in the contest and will have the higher probability of winning.

The politician and the bureaucrats know what the outcome of the players will be (in the example above this means knowing (5)) and how the choice of policy (I) and CSF determined by them will affect each group's efforts, the probability of winning, the rent dissipation and the expected net payoffs in equilibrium. Therefore, they can determine the policy best fitting their political platform (Epstein and Nitzan, 2007). For example, increasing the proposed migration quota (as will be discussed latter on in the paper) can change the contestants' stakes such that the underdog (the one with the smaller stake under the old policy) can become a favorite contestant (the one with the bigger stake). This will affect the outcome of the contest. 
The politician/government knows how a change in policy $I$ will affect the equilibrium. As commonly assumed in the political economy literature (Persson and Tabellini, 2000, Grossman and Helpman, 2001, Epstein and Nitzan, 2007) let the government's objective function be a weighted average of the expected social welfare and lobbying efforts:

$$
G(.)=\alpha\left(E\left(u_{1}\right)+E\left(u_{2}\right)\right)+(1-\alpha)\left(x_{1}+x_{2}\right)
$$

Using (3) we can rewrite (6) in the following way

$$
G(.)=\alpha\left(\operatorname{Pr}_{1} n_{1}(I)+\operatorname{Pr}_{2} n_{2}(I)\right)+(1-2 \alpha)\left(x_{1}+x_{2}\right)
$$

The parameters $\alpha$ and $(1-\alpha)^{5}$ are the weights assigned to the expected social welfare and the contestants' lobbying outlays: $0 \leq \alpha \leq 1$. The parameter $\alpha$ represents the political culture of the government. It reflects the allocation of the contestants' expenditures between wasteful and non-wasteful lobbying resources. It also reflects the commitments of the regulator to the public interest and to his narrow interest of collecting the contestants' expenditures. Increased politicization, namely, a higher (1$\alpha$ ), implies that the government assigns more emphasis to the transfers (the interest group's investments) from the interest groups and is less concerned about welfare. A government with a short horizon may indeed put a larger emphasis on the transfers rather than on the well being of the interest groups. The degree of politicization depends on the norms and the culture which exists in the country. If the enhancement of self-interest is a highly respected norm in the economy and bribes are tolerated to some extent, then even if the government has a long horizon, it may still assign a high 
weight to the transfers. In such a case receiving transfers from the interest groups is considered by the public as a normal action which does not necessarily reduce the politicians' probability of being re-elected. This is not the case in countries where bribes and transfers are not part of the culture. Countries with politicians having different levels political culture ( $\alpha$ ) will have different public policies, even though the economic environment of the two countries is identical.

In the example we described above we showed that even if the Prime Minster wishes to maximize social welfare, namely $\alpha=1$ and $1-\alpha=0$, the Prime Minister will determine a policy that may reduce social welfare. In the case that $0<\alpha<1$ it is clear that the Prime Minister would determine a more extreme policy which would decrease social welfare even further.

In order to illustrate the choice of an optimal public policy consider the following situation. Player 1 represents the capital owners who favor migration and player 2 represents the workers' union opposing migration. Assume that the politician can create a policy that increases the stakes of the capital owners $\left(n_{1}\right)$ without changing the stakes of the workers' union $\left(n_{2}\right)$. This change in policy could be a proposed policy to change the terms of migrants' employment without changing the migration quota. By this new policy the benefits the employers have increased (the employers stakes have increased), while it does not change the union's stakes:

$$
\frac{\partial n_{1}}{\partial I}>0 \text { and } \frac{\partial n_{2}}{\partial I}<0 \text {. Assuming that the CSF is a non discrimination logit }
$$

function (see equation (4)) we obtain:

$$
\frac{\partial x_{1}^{*}}{\partial n_{1}}=\frac{2 n_{1} n_{2}^{2}}{\left(n_{1}+n_{2}\right)^{3}}>0, \frac{\partial x_{2}^{*}}{\partial n_{1}}=\frac{n_{1} n_{2}\left(n_{1}-n_{2}\right)}{\left(n_{1}+n_{2}\right)^{3}}, \frac{\partial X^{*}}{\partial n_{1}}=\frac{n_{2}^{2}}{\left(n_{1}+n_{2}\right)^{2}}>0
$$

and 


$$
\frac{\partial E\left(u_{1}^{*}\right)}{\partial n_{1}}=\frac{3 n_{1}^{3}+3 n_{1}^{2} n_{2}}{\left(n_{i}+n_{j}\right)^{3}}>0, \quad \frac{\partial E\left(u_{2}^{*}\right)}{\partial n_{1}}=\frac{-2 n_{2}^{3}}{\left(n_{i}+n_{j}\right)^{3}}<0
$$

Increasing the stakes of the capital owners (player 1) increases their efforts in the contest $\frac{\partial x_{1}^{*}}{\partial n_{1}}>0$ and it may increase or decrease the workers' union's efforts (player 2). However, even if the union's effort decreases the increase in capital owners effort is higher than the decrease in the unions change in effort : $\frac{\partial X^{*}}{\partial n_{1}}>0$. This increase in the capital owner's stake will increase their expected net payoff and will decrease the expected net payoff of the union. It is not clear, however, what will be the total effect on welfare. If the politician only cares about his narrow self interest, $\alpha=0$, then it is clear that such a policy increases the politician's utility, $G($.

At first glance, the model seems to predict that political influence decreases welfare. However, we would think of a more general model in which the politicians use the funds spent by the interest groups to increase their probability of winning the election. Consider the situation in which workers dislike migrants against all economic rationale or that they are just misinformed. Capital owners, on the other hand, understand the potential efficiency gains, that would be good for the economy to raise the immigration quota. Through lobbing and election campaigns, the capital owners can affect policy so that the migration quota will be increased and enhance social welfare.

This basic model holds true not only for a Prime Minister or President of a country, but for every level of decision making even at the lowest level of the family where a parent has to make a decision which affects the members of the family with regard to who will migrate, where to migrate to, when to migrate, etc. In this case, 
social welfare is the welfare of the family and the investments of the groups are the different "investments" made by the different members of the family trying to affect the head of the household's decision.

In the rest of the paper we describe different aspects of how political economy and migration interact. The simple political model just shown governs the different frameworks presented in the literature and can be used to understand the many phenomena of migration policy and outcomes.

\section{Receiving Country}

The effect of migration on the host countries is theoretically unclear. There exists a large literature on the effect migrants may have on the local population, see for example, Benhabib (1996), Borjas (1994), (1995), Gang and Rivera-Batiz (1994), Schmidt, Stilz, and Zimmermann (1994), Zimmermann (1995), Boeri, Hanson and McCormick (2002), Krishnakumar and Müller (2011) and Card, Dustmann and Preston (2011).

One thing is apparent: except in unusual circumstances, Western countries tend to spend significant resources towards limiting the number and/or type of immigrants they allow into their countries. These limits are upheld via both border controls, through which undesired people are blocked from entering, and via internal enforcement, whereby undesirable people are apprehended and expelled from the country (Ethier, 1986).

There are many possible reasons why the host country would want migrants: migrants may be a way to receive low cost labor, to increase the supply of labor in order to decrease wages, scarcity of workers in certain fields or professions; in economies of aging populations where there are low fertility levels, migration can be 
a solution to demographic problems affecting sustainability of intergenerational transfers (Hillman, 2002). All these elements differently impact members of society and their stakes (the value of $n_{\mathrm{i}}$ presented the previous section).

In the 1997 Euro-barometer survey, immigration turns out to be one of the three most significant political or social issues. It is not surprising therefore that, with a large number of migrants, the high unemployment rate in some of the host countries, xenophobia, and the perceived effect the migrants have on the local population (workers and capital owners), migration policy is becoming an important issue in some of the developed countries and, in particular, it has become a central issue in the elections held in these countries. ${ }^{6}$

In an analysis, of a welfare-state determinants of individual attitudes toward immigrants and their interaction with labor market drivers of preferences, it has been shown, that in countries where immigration is unskilled, income is negatively correlated with pro-immigration preferences, while skill is positively correlated with them. These relationships are reversed in economies characterized by skilled migration (see Facchini and Mayda, 2009). ${ }^{7}$

The utility of the local population (their stakes) may also be negatively related to the number of migrants as a result of xenophobia, desire not to interact with different cultures, the effect of the finance of public goods as well as welfare and distributional effects which adversely affect the local population. Migration policy involves a large range of issues such as legal and illegal migrants, temporary and permanent migration, high skilled and low skilled migration, asylum seekers and family unification. Many studies have been carried out regarding the optimal migration policy and the effects which different migration policies might have on the host country. Concern has been focused on whether to impose capital and skill 
requirements on the migrants, Benhabib (1996), on the alternative future policy options, given past experience, Zimmermann (1995), on whether a reform of immigration policy can alone resolve the fiscal problems associated with the aging of the baby boom generation, Storesletten (2000), on the preferred policy regarding temporary and illegal migration, Epstein (2003), Epstein, Hillman and Weiss (1999) and Hillman and Weiss (1999), on the migration policy implications, Bauer, Lofstrom and Zimmermann (2000) and, on migration policy in an efficiency wage setting, Epstein and Hillman (2003). ${ }^{8}$ Thus the struggle over migration policy is becoming a very important issue in the EU and in the US.

We now divide the discussion into four main topics. The first topic is voter's attitude towards immigrants. Attitudes are not always a direct function of economic outcome and may well be policy related. Policy is determined many times by political constraints facing the politicians and interest groups. Thus, the political economy environment plays an important role in determining voters' attitude towards migrants. The second topic deals with migration quotas. Migration quotas are not always welfare enhancing. Quotas may be determined by the influence of interest groups and political constraints. Migration quotas are an essential element and may well be affected by political constraints and affect voter behavior. The third topic is assimilation and the desire to maintain a different culture by immigrants. In this section we will discuss how political entities try to distinguish the migrants from the local population. These groups can be the local population or even other migrants who obtain rents from distinguishing themselves from the local population. The fourth and last topic is networks and international trade. Political economy plays an important role in determining to what extent there will be trade, who will benefit and who will lose, who will be in favor and who will be against. 


\subsection{Voters' Attitudes to Immigrants}

Studies of the political economy of immigration policy investigate voters' attitudes to immigrants (for example Mazza and van Winden 1996, Benhabib 1996, Hillman and Weiss 1999). Such studies require an underlying basis which explains why a voter might personally support or object to immigration. One basis that identifies personal gains and losses from immigration is the standard full-employment model of international trade and factor movements, where voter sentiment to immigration is derived from changes in real incomes, with some persons gaining from immigration and others losing. There are, on the other hand, circumstances where there are no domestic losers from immigration. Immigration can result in skill upgrading that is beneficial for all domestic workers (Fuest and Thum, 2001).

Benefits from an expanded tax base require that immigrants add to the taxpaying population. If unemployed immigrants are beneficiaries of tax-financed income transfers, immigrants increase government expenditures rather than adding to the domestic tax base. Voters perceiving the tax-financed income transfers to immigrants might then raise questions about the benefits from immigration and determine whether the stakes are positive or negative. ${ }^{9}$

The endogenous determination of policy towards international factor mobility where domestic interest groups bid for protection from the government and the incumbent politicians maximize a welfare function that depends both on domestic voters' welfare and contributions collected (each of the groups welfare is described by equation (3) and the total benefit of the ruling politician by equation, (6) emphasize 
the degree of complementarity among inputs. This determines the outcome (Facchini, and Willmann, 2005).

As presented in the model in section 2, the policy determined by the politicians affects the stakes of the different interest groups. These stakes may be objective or subjective benefits and costs. Thus they are a function of the sentiments of the local population to the migrants. Bauer, Lofstrom and Zimmermann (2000) show that it is difficult to disentangle the extent to which the sentiments of the population are in line with policy or policy is in line with sentiments. The underlying factors that determine attitudes towards immigration are presented in their study in an analysis of individual data from selected 12 OECD countries. In their paper, the authors explore the possibility that immigration policy may affect the labour market assimilation of immigrants and consequently the attitudes of the native population towards immigrants. In line with the model presented above, the authors state that there are at least indications that immigration policies affect the attitudes of the native population towards immigrants. They find that natives in countries selecting immigrants on their skills are more likely to think that immigrants are generally good for the economy than are natives in countries which receive mainly asylum seekers and refugees. In terms of the model presented, the first affects the stakes in a positive way (migrants are welfare enhancing), while the migrants that are asylum seekers are have a negative effect on the stakes. Natives in Canada and New Zealand, however, are more concerned that immigration negatively affects their own labour market situation, whereas in countries that receive mainly noneconomic migrants, natives are mostly concerned about increasing crime rates. Socio-economic characteristics of the respondents such as education, gender and employment status do not seem to explain the major differences in the perception of immigrants across countries. 
Following a different approach, Epstein and Hillman (2003) investigated the efficiency-wage case for benefits from immigration in a welfare state. An efficiencywage view of unemployment suggests a source of benefit for voters from welfareassisted unemployed immigrants. Given the inevitably of unemployment in the efficient worker-disciplining equilibrium, domestic labour might prefer that someone else be unemployed. Immigrants may accept this role, against the alternative of the quality of life offered in the countries which they have chosen to leave.

In their model, employed workers pay the taxes which finance the income transfers to the unemployed and immigrants which, in the first instance displaces national workers from the unemployment pool. The real wage declines because of immigration, but the probability of a local worker being employed increases. Although employed workers finance the income transfers to the unemployed, immigration within designated bounds increases the expected utility of local workers. Since employers benefit from immigration, immigration policies exist which are mutually beneficial for all voters whether they are local employees or employers, although employers will want more immigrants than workers. Under the efficiency wage model unemployment is essential. A public policy that imports migrants so that the immigrants will be unemployed and they will replace the local unemployed workers may well be welfare enhancing, benefiting local workers, capital owners, and thus all voters. In this case, the weight assigned to social welfare as described in the basic model and presented by equation (6) may well equal $1(\alpha=1)$ since in this presentation it would be welfare enhancing to create, at least in the short run, such a migration policy which benefits all. In this situation, theoretical constraints coincide with the benefits of the different groups in the economy and, as such, welfare is maximized. 
To sum up, attitudes towards migrants may or may not be based on real economic outcomes and it is not clear to what extent the sentiments of the population are in line with policy or policy is in line with sentiments. It is clear, however, that immigration policy that imports migrants to be unemployed in the host country may positively affect the local employees and capital owner's sentiments (the voters) towards migration.

\subsection{Migration Quotas}

Even though there is a large literature concerning migration policy, there are very few studies on how political constraints affect this policy. Hanson (2010) examines high-income country motives for restricting immigration. Abundant evidence suggests that allowing labor to move from low-income to high-income countries would yield substantial gains in global income. Yet, most high-income countries impose strict limits on labor inflows and set their admission policies unilaterally. A core principle underlying the World Trade Organization is reciprocity in tariff setting. When it comes to migration from poor to rich countries, however, labor flows are rarely bidirectional, making reciprocity moot and leaving labor importers with all the bargaining power. One motivation for barriers to labor inflows is political pressure from groups which are hurt by immigration. Raising immigration would depend on creating mechanisms to transfer income from those that immigration helps to those that it hurts (Hanson, 2010).

Under a theoretical model of interest group competition, the number of immigrants allowed into a country is the outcome of a costly political lobbying process between those wishing to increase the number of migrants (e.g. the capital 
owners) and those wishing to decrease the number of migrants entering into the economy (e.g. the workers' union).

As presented in the basic model section above (section 2), the approval of a migration policy hinges on the lobbying efforts of the groups competing for the approval and rejection of the proposed policy (Amegashie, 2004 and Epstein and Nitzan, 2006). In contrast to Amegashie (2004), Epstein and Nitzan (2006) develop three alternative frameworks that allow a general contest success function which is positively affected by the different lobbying efforts of the contestants. As presented above, there are two interest groups: one against the proposed quota (group 2) and the other in favor of it (group 1). Those against the migrants include: workers who fear that they will be adversely affected by migration, anti-immigrant groups, immigrants of previous generations who prefer not to be joined by other migrants in the host country, etc. On the other side stand the capital owners who prefer a higher migration quota than do the workers.

Based on the framework developed by Epstein and Nitzan (2004, 2006), the objective of their paper was to look at political-economic considerations that determine migration quotas. They begin the analysis by considering the optimal migration quotas of the workers' union and the capital owners, assuming that each group behaves non-strategically, sincerely revealing its preferred policy. The support of these (first best) policies is plausible, if each group believes that its preferred policy has no effect on the implemented policy. Then they examine the preferred policy proposals when the interest groups recognize that the approval or rejection of their preferred policy depends on their lobbying efforts. Their analysis clarifies that the stats-quo has an important role to play in determining the bureaucrat's proposal and the likelihood of its approval. 
In this setting the government does not intervene in the determination of the quota proposal, $I$. Thus even though the objective of the government may be described as in equation (6) they are not active players (the game between the two players is defined by equation (3)). They present a two stage model. In the first stage each group proposes a policy and in the second stage they compete over the approval or rejection of the policy. In terms of the model presented above, each player will determine the optimal policy that maximizes their expected net payoff as presented in equation (3) (in the specific case of the logit CSF equation (5)) knowing what their optimal investment will be for each policy they propose. By their first result, the effect of lobbying on the random behaviour of the bureaucrat is compromise enhancing. That is, both the workers and the capital owners moderate their proposals when lobbying affects the approval of their supported policies. However, even though lobbying induces the contestants to propose "closer" policies, the proposals do not coincide since both can gain from not proposing the same policy.

In contrast to their first result, the effect of government intervention in determining the proposed quota, $I$, on the nature of the quota is ambiguous. That is, when a bureaucrat proposes a migration quota, I, (such that it maximizes the government's objective function as described by equation 6), the proposed quota need not be compromise enhancing, relative to the proposal of the workers or the capital owners in the previous case. The implemented quota can even be more extreme (higher) than the optimal quota of the capital owners in the non-strategic setting. The second result specifies the conditions which give rise to moderate and extreme quota determination by the government. They provide conditions which ensure that the proposed policy will never coincide with one of the groups' preferred policy. The main idea for this result is that the politician may propose a policy that creates high 
stakes for both parties that pushes the players to invest a high level of resources in the contest and thus for a low level of $\alpha$ increases the utility of the politician.

The status-quo determines the stakes of the contestants. The stakes are defined in section 2 by the difference between $u$ and $v$. They are the difference between the utility obtained under the status-quo and the benefit obtained under the new policy. The existing status-quo policy plays a major role in determining the proposed policy. In different economies with different status-quotas one would see different proposals.

Finally, they consider the effect of changes in the weight assigned by the bureaucrat to the public well being on the proposed quota (political culture) which is represented by the parameter $\alpha$ described in equation (6). It is shown that a decrease, in the weight assigned by the bureaucrat to social welfare, may increase or decrease the migration policy. The ambiguity is due to the ambiguity of the effect of a change in the proposed migration policy, I, on the total lobbying efforts of the workers and the capital owners $\left(x_{1}+x_{2}=X\right)$ in the contest over the approval or rejection of the proposed quota.

Quota may also be very small. Using an efficiency wage model, Epstein, Kunze and Ward (2009) present empirical evidence from a firm level data set collected in 2000 on the demand for high-skilled workers, including foreign workers, in Europe and its determinants. The major findings are that a fraction of high-skilled workers recruited from the international labour market is very small, and that foreign and domestic workers are very similar in terms of their formal education (measured by specialisation subject) and their job characteristics. They suggest an efficiency wage model to explain why firms recruit foreign workers in small numbers, and why they are willing to pay immigrants the same wage as local workers, whilst at the same 
time also paying for their moving costs, despite the similar human capital profile of immigrants to domestic workers. Their explanation, for this small number of immigrants, is that these immigrants are used as a signal to the local workers. The presence of the immigrants is signalling to the local workers that if they do not work efficiently, the employer can bring more immigrants to replace the local workers. By doing so the employer achieves a high level of efficiency from the workers.

To sum up, evidence suggests that allowing labor to move from low-income to high-income countries would yield gains in global income, and yet most high-income countries impose restriction on migration. Political constraints can give an explanation to this phenomenon. Under a political economy framework it has been shown that status-quo policy has an important role in determining the bureaucrat's/politician's proposal and the likelihood of its approval. Without intervention of the politicians, both the workers and the capital owners moderate their proposals when lobbying affects outcome. However, when a bureaucrat proposes a migration quota it need not be compromise enhancing. The implemented quota can even be more extreme than the optimal quota of the capital owners in the nonstrategic setting and is a function of the political culture of the politicians. Thus in different countries with different political cultures exhibit different policies.

\subsection{Assimilate and Maintaining Cultural and Heritage}

Minority ethnic group participation in labor markets is quite complex and in many ways different from that of citizens belonging to a nation's majority ethnicity. Studies of minorities around the world show, with few exceptions, that they tend to earn wages substantially below those of comparable majority workers (for example, Altonji and Blank 1999, Blau and Kahn, 2006, 2007, Bhaumik, Gang and Yun, 2006). 
Partly, this reflects a failure on the part of the minority group to undertake the effort to assimilate with the majority (Constant, Gataullina and Zimmermann, 2009). "Lack of effort" can arise from the desire to maintain a cultural heritage or separate identity which would be lost or reduced if the group assimilated. The failure to take active steps to assimilate can also arise in the face of high adjustment costs, such as inadequate language skills, intergenerational familial conflicts, and, in the case of immigrants, lack of knowledge about the host country labor market (Chiswick and Miller, 1995, 1996, Bauer, Epstein and Gang, 2005). Yet for immigrants and their descendants, as length of time in the host country increases, assimilation generally creeps in and various immigrant labor market indicators approach those of comparable majority workers. On occasion, minority workers out-perform majority workers (Chiswick, 1977, Deutsch, Epstein and Lecker, 2006).

The degree to which the majority welcomes the minority plays an important role in assimilation. Often, the majority is less than welcoming, blaming the minority for depressing wages and displacing majority. There is mixed evidence on the impact of minorities on majority wages (Gang and Rivera-Batiz 1994, Gang, Rivera-Batiz and Yun 2002). Whether minorities actually lower wages and increase employment, or not, the perception exists that they do so. Because of this perception the majority may take active steps to discourage minority assimilation - discrimination, isolation, and so on. These majority activities can be seen as harassment activities.

Often the efforts of the minority and the majority are mediated through political institutions. These institutions exist in both the minority and majority worlds. They could be, for example, political parties, trade organizations or unions. These are organizations which are able to overcome the free-rider problem, individual members of each group move from the actions they desire to take, to actually taking the actions. 
Yet, while an organization's purpose may be to represent the members of their group, the interests' of the organization and that of its members do not always coincide.

Epstein and Gang (2009) are interested in why migrants are so often at a disadvantage relative to the local population, the circumstances under which their status changes or stagnates over time, and role public policy can play. Assimilation efforts by the migrants, harassment by the local population and time, are the three elements that determine how well the migrants do in comparison to the local population. In their paper, they examine the consequences of increases in the numbers of migrant members, time, and the role of the political entity. They construct a model in which there are four actors: the members of the local population, the migrants and the organizations which represents them. In terms of the model presented above, each group is represented by an objective function as presented in equation (3). Over time, the political entity representing the migrants and the members of the local population exhibit different interests in assimilating and in maintaining their cultural identity. For example, Lazear (1999) suggests that rational immigrants' efforts to assimilate into the majority culture are inversely related to the size of the minority. The reasoning for this is that if the migrant enclave is sufficiently large, migrants do not need the local population for economic reasons and, as a result, the cost of not assimilating decreases and they may even have a net cost for assimilating. In such a case, the migrants would want to fight to hold on to their culture and not assimilate. In the model presented in section 2 one would need to add a time element and the size of the network of migrants to the stakes to obtain these results. With time and as the size of the enclave increases the stakes change and the and as a result the efforts in the contest. Epstein and Gang (2009) analyses a theoretical game model of ethnic competition between the local population in a 
country and the migrants under which each group invests effort (lobbying activities) to obtain their goal (these are denoted by $x$ in the model presented above). ${ }^{10}$

Moreover, there exist foundations with resources which wish to help migrants. There is also a foundation which works indirectly, offering grants to groups investing efforts to help migrants (for example in the USA there is the MacArthur Foundation and the Ford Foundation.) The foundation offers a prize (grant) for which the groups compete. The competition is such that the one that invests more resources in helping migrants has a higher probability of winning and thus obtains even more resources. The prize and the efforts determine the contest success function determined in equation 3. In a different paper, Epstein and Gang (2010) address how the foundation elicits the most effort from the different "grass roots" groups. In the model presented above the stakes determined in equation (3) are the prizes each group would obtain while the probability of success is determined by the contest success function foundation.

Each group wants the rewards for implementing its own plan, believing its proposal will best help its countrymen. Each group seeks to lead immigrant society, and capture the prize rewarded by the foundation. They may aim to achieve a certain degree of assimilation on the part of immigrants, though each group has its own strategy. They may differ on the degree of cultural identity they want to maintain (see, for example, Lazear, 1999, Gang and Zimmermann, 2000, Dustmann, Fabbri and Preston, 2004 and Kahanec, 2006).

Epstein and Gang (2010) describe and compare two mechanisms for rewarding groups for their efforts. (1) Absolute ranking which is a contest between the groups where the winning group receives all the grants. Those who take the most action, or those who are perceived as having taken the most action, win, and acquire 
the entire grant. In terms of the model presented in section 2 this would mean that the contest success function would be the all pay action. (2) Relative ranking, the groups compete against each other and obtain a grant relative to the amount of effort invested in the contest. This can be seen as a lottery contest (logit contest success function) in which each obtains a grant proportional to the effort invested. In both cases, in equilibrium, the grant obtained is a function of the efforts invested as described in equation (3). The result of a non-discriminating contest is presented by equation (5). Epstein and Gang (2010) are able to derive a very specific condition allowing us to see when each of the concerned parties wins and when each loses the contests. If the difference, between the groups in terms of the rewards (the stakes, $n_{i}$, presented in equation 3 above), they can obtain from helping the country is not sufficiently large, all parties - the two groups and the foundation itself - prefer the lottery regime relative ranking to an absolute ranking. However, if the difference, between the groups (in terms of the rewards that can be obtained), is sufficiently large, then the group with the low benefit, group 2, prefers the relative ranking regime while the other group and the foundation prefer the absolute ranking since in such a contest they would benefit more.

To sum up, economic assimilation is not always achieved. There are many different forces that affect assimilation. In this part we presented the political constraints affecting assimilation. Different groups have different benefits (rents) from different levels of assimilation. The local population may be against assimilation while representatives of the migrants may also want to discourage assimilation. Some simply want to hold on to their cultural and heritages while other benefit from not assimilating. Interest groups invest effort and time to increase the chances of gaining rents and benefiting from the situation. The groups use their resources to help 
assimilation. If these groups would not have a specific arrow self interest agenda they may not compete for the resources help the assimilation of the migrants. Thus groups having specific narrow agenda seems to be a negative element however in some cases narrow self-interest produces externalities that benefit others.

\subsection{Networks and International Trade}

There is a well-established high quality literature on the role of networks, particularly ethnic networks, in international trade. ${ }^{11}$ Ethnic networks are a way of overcoming informal barriers (information costs, risk and uncertainty) to trade by building trust and substituting for the difficulty of enforcing contracts internationally. The networks we are interested in considering here are those which are formed between migrants and natives in the host country and between migrants and their home country.

As presented in Gradstein and Schiff (2006), the local population and immigrants may battle each other about the economic position of the immigrant in the host country. Immigrants, while desiring to assimilate into the host country's culture, may at some point decide that their native heritage is something to hold onto. These forces will impact international trade.

Ethnic networks are not fixed, and we expect them to change as immigrants assimilate. We can think of two extreme cases: (1) when immigrants very quickly assimilate, there will be no ethnic networks and no gains from them for international trade. (2) When immigrant groups live and work in their own ghetto, with little or no contact with natives, the ethnic enclave is really an extension of the home country and it is questionable whether the effects on international trade will be any more than marginally positive. With just a little less isolation we should see trade gains. Over 
time, and as a result of immigrant desires for assimilation and host country attitudes, the role networks play changes, with consequences for the international economy.

Epstein and Gang (2006) explicitly model the role immigrant assimilation plays in international trade. They construct a model in which there are three groups of actors, the native-born (local population) and two groups of migrants, those who are involved in international trade and those who are not (these can be seen as three groups each having different rents as presented in equation (2) above). ${ }^{12}$ In this simple model, competition may lower native-born wages so natives undertake costly discrimination actions against the migrants, while migrants generally are assimilating into the host country's culture. This picture of assimilation is simplified, focusing on the essential elements of migrant behavior in a host country, and the host country's receptivity to immigrants. Migrants want to assimilate, and as they assimilate their consumption patter comes to mimic those of natives. Natives, fearful of lost earnings, try to keep immigrants isolated. Over time, sub-groups of migrants, who cater to the migrant community, will take action against assimilation, arguing for maintaining elements of their cultural heritage and therefore the sub-groups own rents. Though basic, the model allows us to gain insights that are helpful for understanding more complex assimilation scenarios. Migrants and natives may possess asymmetrical ability and productivity. The degree of asymmetry will play a role in determining the intensity of assimilation activities by migrants and discrimination activities by natives. One way of looking at the asymmetry between the groups is in their benefits (rents) as presented in the model above. The value of the rents may change with time and as the assimilation process moves forward. In turn, these determine the expansion and contraction of trade between migrants' host and home country. Over time, migrant traders and migrant employees exhibit different interests in assimilation and 
in maintaining their cultural identity, and the interplay of their conflict, with the actions of the native-born over time, provides further insights into the connection between ethnic networks and international trade.

Thus, migration and assimilation play an important role in international trade. Migrants are a bridge to international trade since they have the knowledge of the home country and the host country. Over time, as assimilation increases, international trade may be affected and those who will lose out from the assimilation process will fight to hold on to traditions and heritage in order to preserve the rents they can obtain from the situation.

\section{The Sending Country}

Emigration decisions can be categorized by a push-pull distinction (Zimmermann 1994). That is, people may emigrate because they are pushed by adversity from their original country, or they may be pulled to a new country by the advantages the new location offers. Or there may, of course, be a combination of both influences present.

Epstein, Hillman, and Ursprung, (1999) are concerned with involuntary push emigration. They present a model which describes how emigration is tied to privileged endogenous income redistribution. Because of the privileged redistribution, people who could, in principle, be better off in their own countries nonetheless find themselves compelled to emigrate.

The privilege which determines the extent to which a person gains or losses from redistribution of income is contestable. They model a rent-seeking contest similar to the one presented in section 2 above, where the contest is locational and offers multiple prizes (some negative) depending on a person's equilibrium distance 
from the leader (the "king"). Time and resources are used in ingratiating themselves with the leader. The resources are determined by the values of $x$ as described in the basic model presented above and the proximity to the leader is determined by the contest success function. People differ in their productive abilities, and hence in their opportunity costs of using time and resources in ingratiating activities. In their paper Epstein, Hillman, and Ursprung, (1999) establish who, under these circumstances, has the greater incentive to emigrate, the more productive or the less productive of the king's subjects? The answer is created by the outcome of the domestic contest for privilege. Those furthest from the leader are the least privileged, and have the greater incentive to emigrate. If the most productive in the population finish the contest furthest from the leader, they emigrate (if they can), so depriving the economy of the most useful segments of the tax base. If the less productive finish the contest furthest from the leader, it is they who emigrate (if they can). In the first case there is the phenomenon which has been described as a brain drain. In the second case, the recipient countries find themselves host to unskilled (and perhaps illegally present) foreign labor.

Applying the Tullock (1980) contest success function to the contest (equation (4)) for privilege, generates the least productive, with the lower opportunity costs, of spending time to make themselves liked to the leader, end up not migrating. The most productive end up furthest from the leader and have the incentive to migrate. In their paper they also consider a contest-success function that can be interpreted as representing "difficult" contests. The idea of "difficulty" is that rent-seeking efforts by others spoil the effect of a person's own efforts. In this contest there is an advantage to being able to make larger rent-seeking outlays. Resources are quickly 
eaten up in these "difficult" contests. The outcome of such a contest is that the more productive members of the population become closer to the leader and do not migrate.

The model is, in its general intent, a portrayal of the non-democratic institutions of various developing countries where proximity to an autocratic ruler influences a person's economic fortune (see Tullock 1987 on autocracy). In particular, in less developed countries where support from the military has sustained autocratic government, there is documented evidence of rent allocations which reflect privileged proximity to the countries' rulers (Kimyeni and Mbaku 1995).

On a different aspect Epstein and Kahana (2008) discuses emigration policy as a result of political constraints in order to decrease child labor by encouraging temporary emigration. It emerges that the remittances sent by the emigrating parents together with the decrease in the labor force, as a result of migration, might enable not only their children, but also others, to stop working even upon the return of the emigrant parents.

The decision, where to migrate to, is complex. Bilateral flows of international migrants exhibit tremendous variance both across destination countries and over time. Leblang, Fitzgerald and Teets (2009) argue that along with economic and social conditions migrants consider the political environment when choosing among various destinations. Specifically they hypothesize that a country's citizenship policy regime and the strength of support for radical right parties are key determinants of destination choice. They test their hypotheses using an original data set of bilateral migration flows from 178 countries of origin into 22 destination countries over the period 1962-2006. They confront the challenge that both the citizenship 
policy regime and radical right party support are endogenous; that they are in part a consequence of international migration.

Linking the sending and receiving countries together through illegal migration, Dula, Kahana and Lecker (2006) suggest a political economy such that the receiving country should direct some of the resources earmarked for coping with the problem of the illegal flow of workers to financially supporting the source countries, allowing them to compete among themselves for such aid. This support would be allocated according to the relative effort made by each source country in curbing illegal immigration, thereby motivating them to moderate the phenomenon. This level of transfer would be a function of the different efforts the interest groups in both countries invest to increase and decrease illegal migration.

The proximity to the center of power in the home country is a result of a political competition between different individuals. The type of contest determines who will emigrate and who will stay. Will it be the productive or the less productive individuals? In this section we presented how political constraints affect migration decisions of the local population and will affect both the home country (those who will stay) and the host country (who will arrive), and, as such, will affect employment and income in the home and destination countries. Also, political bilateral connections between countries could also impose migration restrictions.

\section{Concluding Remarks}

In the paper we tried to point out the effect of political economy on the migration in its different levels. Political economy has an important role in determining the different outcomes. Bauer, Lofstrom and Zimmermann (2000) show that it is difficult 
to disentangle to what extent the sentiments of the population are in line with policy or policy is in line with sentiments while Facchini and Mayda (2010) make a link between public opinion towards migration and public policy. Public opinion, interest groups and social welfare, play an important role in the determining policy. We started by presenting a basic model of competition between two interest groups, one favoring migration and the other opposing. We then extended the model to the case where government, knowing the outcome of the struggle between the two groups, determines the optimal migration policy in order to maximize a combination of social welfare and governments (politicians) self-interest. Throughout the paper we used the simplified political model to show that it can be the basic model that governs the different frameworks presented in the literature.

Most of the literature on the political economy of migration is related to the host country. It deals with migration policy, assimilation efforts and prevention efforts by the local population. There is also a smaller amount of studies which deal with the sending country's political economy that deals with policies to limit and promote emigration. There are only a small number of studies which deal with the political issues that involve the migration at the household level. On this topic there is still a lot of work need. ${ }^{13}$

Migration starts at the family level. The family has to determine if to migrate and if so, which of the members of the family should migrate. Should the entire family migrate or should only one representative of the family? Who should be the representative that migrates? The decision of where to migrate is not always clear and obvious: should they migrate to a destination where many others before them have gone (networks and herd effects) or should they go to a new destination? On the 
arrival in the new destination should they keep on their traditions or accept the new traditions of the local population. These are only a few questions which a family faces during the process of migration. It starts with the decision regarding whether to migrate and finishes long after the family has settled in the new destination. The family in many cases is not one entity and all its members do not always agree with each other. Many conflicts arise between and within the members of the direct and extended family (this situation can be described using the model presented in section $2)^{14}$. Many political economic issues arise trying to solve these questions inside the family. A lot of these issues are not dealt within the literature and should be developed in the future.

As we presented above, the political economy approach takes into consideration many elements that enable us to understand better the economic outcomes of migration. It helps us understand better why similar countries would have different public policy and why different governments in the same country have different policies. We also can understand the extent of investment of wasteful resources in trying to affect public policy. The role of the politicians and their political culture, the effect interest groups have on policy, and the assimilation of immigrants as part of the political framework. Political economy is an essential part of the migration process, starting at the family level and claiming up the ladder through firms, interest groups and unions and ending up at civil servants, politicians and government policy. 


\section{References}

Altonji, Joshep G. and Rebecca M. Blank (1999), 'Race and gender in the Labor Market', in Orley Ashenfelter and David Card (eds.), Handbook of Labor Economics, 3C, Elsevier Science B.V. Amsterdam, 3143-3259.

Amegashie, Atsu J. (2004), 'A political economy model of immigration quotas', Economics of Governance 5, 255-267.

Anderson, Kym and Alan L. Winters (2008),'The challenge of reducing international trade and migration benefits', Available at SSRN: http://ssrn.com/abstract=1141665.

Bauer, Thomas, Gil S. Epstein and Ira N. Gang (2005), 'Enclaves, language and the location choice of migrants", Journal of Population Economics, 18 (4), 649662.

Bauer, Thomas, Gil S. Epstein and Ira N. Gang (2007) "The Influence of Stocks and Flows on Migrants' Location Choices" Research in Labor Economics 26, 199229.

Bauer, Thomas K. and Klaus F. Zimmermann (eds) (2002), The economics of Migration, Edward Elgar Publishing.

Bauer, Thomas K. Magnus Lofstrom and Klaus F. Zimmermann (2000), 'Immigration policy, assimilation of immigrants and natives' sentiments towards immigrants: evidence from 12 OECD-countries', Swedish Economic Policy Review, 7 (2), 11-53.

Benhabib, Jess (1996), 'On the political economy of immigration', European Economic Review, 40, 1737-1743.

Bisin, Albero and Thierry Verdier (2010), 'The economics of cultural transmission and socialization', NBER Working Paper No. 16512.

Bhaumik, Sumon K., Ira N. Gang, and Myeong-Su Yun (2006), 'Ethnic conflict and economic disparity: Serbians and Albanians in Kosovo', Journal of Comparative Economics, 34(4), 754-773.

Blau, Francine D. and Lawrence M. Kahn (2006), 'The US gender pay gap in the 1990s: Slowing convergence', Industrial and Labor Relations Review, 60(1), 45-66.

Blau, Francine D. and Lawrence M. Kahn (2007), 'The gender pay gap', The Economists' Voice: 4(4).

Boeri, Tito, Gordon H. Hanson and Barry McCormick (eds) (2002), Immigration Policy and the Welfare System, Oxford University Press.

Borjas, Gorge J. (1994), 'The economics of immigration', Journal of Economics Literature 32, 1667-1717.

Borjas, Gorge J. (1994), 'Assimilation and Changes in Cohort Quality Revisited: What Happened to Immigration Earnings in the 1980s?" Journal of Labor Economics, 13(2), 201-245.

Card, David, Christian Dustmann, Ian Preston (2011), 'Immigration, wages and compositional amenities' Journal of the European Economic Association, forthcoming.

Chiswick, Barry R. and Paul W. Miller (1995), 'The endogeneity between language and earnings: international analyses, Journal of Labor Economics, 13, 246288.

Chiswick, Barry R. and Paul W. Miller (1996), 'Ethnic networks and language proficiency among immigrants, Journal of Population Economics, 9,19-36. 
Chiswick, Barry R. (1977), 'Sons of immigrants: Are they at an earnings disadvantage?', American Economic Review, Papers and Proceedings, 376380.

Constant, Amelie F., Liliya, Gataullina and Klaus F. Zimmermann (2009), 'Ethnosizing immigrants', Journal of Economic and Behavioral Organization, 69(3), 274-287.

Deutsch, Joseph, Gil S. Epstein and Tikva Lecker (2006), 'Multi-generation model of immigrant earnings: Theory and application, Research in Labor Economics, 24,217-234.

Dustmann, Christian, Francesca Fabbri, and Ian Preston (2004), Ethnic concentration, prejudice and racial harassment of minorities, CReAM Discussion Paper 05/04 (www.econ.ucl.ac.uk/cream/).

Dula, Giora, Nava Kahana and Tikva Lecker (2006), 'How to partly bounce back the struggle against illegal immigration to the source countries" Journal of Population Economics, 19(2), 315-325.

Epstein, Gil S. (2003), 'Labor market interactions between legal and illegal immigrants', Review of Development Economics, 7(1), 30-43.

Epstein, Gil S. (2007), 'Extremism within the family', Journal of Population Economics, 20, 707-715.

Epstein, Gil S. (2010) "Informational Cascades and the Decision to Migrate" in Gil S. Epstein, and Ira N. Gang, (Eds), Migration and Culture: Frontiers of Economics and Globalization, volume 8, , Emerald Group Publishing Limited.

Epstein, Gil S. and Arye L. Hillman (2003), 'Unemployed immigrants and voter sentiment in the welfare state', Journal of Public Economics, 87, 1641-1655.

Epstein, Gil S., Arye Hillman and Avi Weiss (1999), 'Creating illegal immigrants', Journal of Population Economics, 12(1), 3-21.

Epstein, Gil S. and Arye L. Hillman and Heinrich Ursprung (1999), 'The king never emigrates', Review of Development Economics, 3(2), 107-121.

Epstein, Gil S. and Ira N. Gang, (2010) "Migration and Culture" in Gil S. Epstein, and Ira N. Gang (Eds), Migration and Culture: Frontiers of Economics and Globalization, volume 8, , Emerald Group Publishing Limited.

Epstein, Gil S. and Ira, N. Gang (2010), 'A political economy of the immigrant assimilation: internal dynamics" in Gil S. Epstein, and Ira N. Gang, (Eds) Migration and Culture: Frontiers of Economics and Globalization, volume 8, Emerald Group Publishing Limited.

Epstein, Gil S. and Nava Kahana (2008), 'Child labor and temporary emigration, Economics Letters, 99(3), 545-548.

Epstein, Gil S. and Shmuel Nitzan (2004), 'Strategic restraint in contests', European Economic Review, 48, 201-210.

Epstein, Gil S. and Shmuel Nitzan (2006), 'Lobbying and compromise', Public Choice, 126(3-4), 317-334.

Epstein, Gil S. and Shmuel Nitzan (2006), "The struggle over migration policy" Journal of Population Economics, 19(4), 703-723.

Ethier, Wilfred J. (1985), 'International trade and labor migration', The American Economic Review, 75(4), 691-707.

Ethier, Wilfred J. (1986), 'Illegal immigration: the host country problem', American Economic Review, 76, 56-71.

Facchini, Giovanni. and Anna M. Mayda (2009), 'Does the welfare state affect individual attitudes towards immigrants: Evidence across countries', Review of Economics and Statistics, 91, 291-314. 
Facchini, Giovanni. and Anna M. Mayda (2010), 'What drives immigration policy? Evidence based on a survey of governments' officials', in Gil S. Epstein, and Ira N. Gang, eds, Frontiers of Economics and Globalization, volume 8, Migration and Culture, Emerald Group Publishing Limited.

Facchini, Giovanni and Gerald Willmann (2005), 'The political economy of international factor mobility', Journal of International Economics, 67(1), 201219.

Fuest, Clemens and Marcel Thum (2001), 'Immigration and skill formation in unionised labour markets', European Journal of Political Economy, 17(3), 557-573.

Gang, Ira N. and Klaus F. Zimmermann (2000), 'Is child like parent? educational attainment and ethnic origin', Journal of Human Resources, 35, 550-569.

Gang, Ira N. and Francisco L. Rivera-Batiz (1994), 'Labor market effects of immigration in the United States and Europe: Substitution vs. Complementarity, Journal of Population Economics, 7, 157-175.

Gang, Ira N., Francisco Rivera-Batiz and, Myeong-Su Yun (2002), 'Economic strain, ethnic concentration and attitudes towards foreigners in the European Union', IZA Discussion Paper 578 (www.iza.org).

Gradstein, Mark and Maurice Schiff (2006), 'The political economy of social exclusion, with implications for immigration policy', Journal of Population Economics, 19(2), 327-344.

Grossman, Gene M. and Elhanan Helpman (2001), Special Interest Politics, Cambridge, MA, M.I.T. Press.

Grossman Gene M, Kenneth S. Rogoff eds. (1997) Handbook of International Economics, vol 3 . Elsevier Science.

Hainmueller, Jens and Michael J. Hiscox (2010), 'Attitudes toward highly skilled and low-skilled immigration: evidence from a survey experiment', American Political Science Review, 104,01, 61.

Hanson, Gordon (2010), 'The governance of migration policy', Journal of Human Development and Capabilities, 11(2), 185-207.

Hansen, Jargen and Magnus Lofstrom (2003)' 'Immigration assimilation and welfare participation: do immigrants assimilate into or out of welfare? Journal of Human Resources, XXXVIII(1), 74-98.

Hillman, Arye L. (2002), 'Immigration and intergenerational transfers', In: Economic Policy for Aging Societies, Horst Siebert, editor. Kluwer Academic Publishers, Dordrecht and Boston, 2002, pp. 213 - 26.

Hillman, Arye L. and Avi Weiss (1999), 'A theory of permissible illegal immigration,' European Journal of Political Economy, 15, 585-604.

Hillman, Aryw L. and John G. Riley (1989), 'Politically contestable rents and transfers", Economics and Politics 1, 17-39.

Kahanec, Martin (2006), 'Ethnic specialization and earnings inequality: why being a minority hurts but being a big minority hurts more', IZA Discussion Paper, 2050, (www.iza.org).

Kimyeni, Mwangi S. and John Mukum Mbaku (1995), 'Rents, military elites, and political democracy', European Journal of Political Economy, 11, 699-708.

Krishnakumar, Jaya and Tobias Müller (2011), 'The political economy of immigration in a direct democracy: The case of Switzerland' European Economic Review, forthcoming.

Lazear, Edward P. (1999), 'Culture and language', Journal of Political Economy, 107(6), S95-S126. 
Leblang, David, Jennifer Fitzgerald and Jessica Teets (2009), 'Defying the law of gravity: the political economy of international migration' Available at http://papers.ssrn.com/sol3/papers.cfm?abstract_id=1421326.

Mazza, Isidoro and Frabs W. van Winden (1996), 'A political economy analysis of labor migration and income distribution', Public Choice, 88, 333-363.

Persson, Torsten and Guido Tabellini (2000), Political Economics: Explaining Economic Policy. Cambridge, M.I.T. Press.

Schmidt, Christoph M. Anette Stilz and Klaus F. Zimmermann (1994), 'Mass migration, unions, and government intervention', Journal of Public Economics, 55, 185-201.

Storesletten, Kjetil (2000), 'Sustaining fiscal policy through immigration', Journal of Political Economy, 108, 300-323.

Tullock, Gordon, (1980), 'Efficient rent seeking', in James M. Buchanan, Robert D. Tollison, and Gordon Tullock eds, Toward a Theory of the Rent Seeking Society (Texas A\&M Press, College Station TX), 97-112.

Tullock, Gordon (1987), Autocracy, Kluwer Academic Publishers, Boston and Dordrecht.

Zimmermann, Klaus F. (1994), 'European migration: push and pull', Proceedings of the World Bank Annual Conference.

Zimmermann, Klaus F. (1995), 'Tackling the European migration problem', Journal of Economics Perspectives, 9, 45-62.

${ }^{1}$ Financial support from the Adar Foundation of the Economics Department of BarIlan University is gratefully acknowledged.

2 For example, on the one hand, if the Prime Minister believes that if he is reelected social welfare will be at a level of 2,000. On the other hand, if the opposition is elected social welfare will fall to 1200 . The Prime Minster would be willing to pass legalization to increase the migration quota if it decreases social welfare by less than 800. In this situation, passing legislation which increases the migration quota and decreases welfare is better for society than not passing the legislation and the opposition coming into power.

${ }^{3}$ The most commonly used CSFs are (1) the generalized logit function that generates a winning probability which is proportional to the level of investment in the contest (Tullock, 1980) and (2) the All Pay Auction under which the group that invests the highest amount of resources in the contest wins with certainty (Hillman and Riley, 1989). 
4 The first order condition is $\frac{\partial E\left(u_{i}\right)}{\partial x_{i}}=\frac{x_{j}}{\left(x_{i}+x_{j}\right)^{2}} n_{i}-1=0 \forall i, j=1,2$ and $i \neq j$, while the second order condition, $\frac{\partial^{2} E\left(u_{i}\right)}{\partial x_{i}^{2}}=\frac{-2 x_{j}}{\left(x_{i}+x_{j}\right)^{3}} n_{i}<0 \quad \forall i, j=1,2$ and $i \neq j$, is satisfied.

${ }^{5}$ A politician will only benefit from such a competition between the interest groups if $0<\alpha<0.5$.

${ }^{6}$ Most of the evidence, on the effect of immigration on wages (and employment) for the US, is also ambiguous in the sense that some studies show small positive effects and others small negative effects. Also the European literature largely suggests that those fears are unfounded).

7 Card, Dustmann and Preston (2011) using data for 21 countries in the 2002 European Social Survey, which include a series of questions on the economic and social impacts of immigration, as well as on the desirability of increasing or reducing immigrant inflows, find that individual attitudes toward immigration policy reflect a combination of concerns over conventional economic impacts and compositional amenities, with substantially more weight on the latter.

${ }^{8}$ Other implications of migration policy are studied in Boeri, Hanson and McCormick (2002) and Bauer and Zimmermann (2002), see also references therein.

9 For empirical evidence on tax-financed income transfers to unemployed immigrants in a welfare state (the Swedish case), see Hansen and Lofstrom (2003). Wellisch and Walz (1997) who correspondingly point out how the welfare state can affect the choice between free trade in goods and free immigration. Krishnakumar and Müller (2011) analyze the determination of immigration policy in a direct democratic setting. They formulate a model of voting and participation behaviour 
integrating instrumental and expressive motivations. The model is estimated using data drawn from a survey carried out after a vote in Switzerland in 2000 on a popular initiative proposing to implement immigration restrictions. The results reveal a substantial gap ("participation bias") between attitudes towards immigration in the general population (43\% favorable to restrictions) and the outcome of the vote (26\%). Hainmueller and Hiscox (2010) using an original experimental survey embedded in a nationwide U.S. survey which finds that rich and poor natives are equally opposed to low-skilled immigration in general.

${ }^{10}$ In the United States prominent organizations include: NAACP, HIAS, the AntiCatholic League, the Ku Klux Klan (KKK). In Europe: political parties take either pro- or anti-immigrant positions. There may be multiple competing organizations.

${ }^{11}$ E.g. Ethier (1985), Grossman and Rogoff (1997), Anderson and Winters (2008) and Bauer, Epstein and Gang, 2005).

${ }^{12}$ Migrants are assumed to all be from one home country, and the discussion of trade is with respect to the migrants' host and home countries only. One could also think of networks of migrants from different countries but with the 'same' cultural background (for example Asians, Africans, Arabs, etc.).

13 Bisin and Verdier (2010) review the main contributions of models of cultural transmission, from theoretical and empirical perspectives. They present their implications regarding the long-run population dynamics of cultural traits and cultural heterogeneity, the world's geographical fragmentation by ethnic and religious traits, at any given time. In a narrower framework Epstein (2007) presents a model in which migrants live in two periods. In the first period, children live with their parents. The children are assumed to be born without well-defined cultural traits which they acquire from their parents before becoming adult. In the paper it is shows that parents 
may choose more extreme social ideals than they would have if they didn't have children. The reason for this is that they wish to create a cost for their children for deviating from their ideal. In such a way the parents increase the probability that when the children become adults and have to choose their own way, it will be closer to that of their parents. This choice affects the long run probability of assimilation of the children into the local population.

14 Each group in the model represents a member of the family that has his own preferences and benefits from the different options available. The value of the different options is represented by stakes. Each member of the family can invest resources to affect the choice of the head of the household. The government in this model represents the utility of the head of the household and has also narrower concerns. 